\title{
Regular physical exercise improves cardiac autonomic and muscle vasodilatory responses to isometric exercise in healthy elderly
}

This article was published in the following Dove Press journal:

Clinical Interventions in Aging

28 June 2017

Number of times this article has been viewed

\begin{abstract}
Adriana de Oliveira
Sarmento, ${ }^{1-3}$ Amilton da

Cruz Santos, ${ }^{1,4}$ Ivani Credidio

Trombetta, ${ }^{2,5}$ Marciano

Moacir Dantas, ' Ana Cristina

Oliveira Marques, ${ }^{1,4}$ Leone

Severino do Nascimento, ${ }^{1,4}$

Bruno Teixeira Barbosa, ${ }^{1,2}$

Marcelo Rodrigues Dos

Santos, ${ }^{2}$ Maria do Amparo

Andrade, ${ }^{3}$ Anna Myrna

Jaguaribe-Lima, ${ }^{3,6}$ Maria do

Socorro Brasileiro-Santos ${ }^{1,3,4}$

'Laboratory of Physical Training Studies Applied to Health, Department of Physical Education, Federal University of Paraiba, João Pessoa, Brazil; ' ${ }^{2}$ nit of Cardiovascular Rehabilitation and Exercise Physiology - Heart Institute (InCor/HC-FMUSP), University of São Paulo, São Paulo, Brazil; ${ }^{3}$ Graduate Program in Physiotherapy, Federal University of Pernambuco, Recife, Brazil; ${ }^{4}$ Associate Graduate Program in Physical Education UPE/UFPB, João Pessoa, Brazil; ${ }^{5}$ Graduate Program in Medicine, Universidade Nove de Julho (UNINOVE), São Paulo, Brazil;

${ }^{6}$ Department of Morphology and

Animal Physiology, Federal Rural University of Pernambuco, Recife, Brazil
\end{abstract}

Correspondence: Maria do Socorro Brasileiro-Santos

Universidade Federal da Paraíba,

Departamento de Educação Física,

Cidade Universitária, João Pessoa, PB,

CEP 5805I-900, Brazil

Email sbrasileiro@pq.cnpq.br
Abstract: The objective of this study was to evaluate cardiac autonomic control and muscle vasodilation response during isometric exercise in sedentary and physically active older adults. Twenty healthy participants, 10 sedentary and 10 physically active older adults, were evaluated and paired by gender, age, and body mass index. Sympathetic and parasympathetic cardiac activity (spectral and symbolic heart rate analysis) and muscle blood flow (venous occlusion plethysmography) were measured for 10 minutes at rest (baseline) and during 3 minutes of isometric handgrip exercise at $30 \%$ of the maximum voluntary contraction (sympathetic excitatory maneuver). Variables were analyzed at baseline and during 3 minutes of isometric exercise. Cardiac autonomic parameters were analyzed by Wilcoxon and Mann-Whitney tests. Muscle vasodilatory response was analyzed by repeated-measures analysis of variance followed by Tukey's post hoc test. Sedentary older adults had higher cardiac sympathetic activity compared to physically active older adult subjects at baseline ( $63.13 \pm 3.31$ vs $50.45 \pm 3.55 \mathrm{nu}, P=0.02)$. The variance (heart rate variability index) was increased in active older adults $(1,438.64 \pm 448.90$ vs $1,402.92 \pm 385.14 \mathrm{~ms}, P=0.02$ ), and cardiac sympathetic activity (symbolic analysis) was increased in sedentary older adults $(5,660.91 \pm 1,626.72$ vs $4,381.35 \pm 1,852.87, P=0.03)$ during isometric handgrip exercise. Sedentary older adults showed higher cardiac sympathetic activity (spectral analysis) $(71.29 \pm 4.40$ vs $58.30 \pm 3.50 \mathrm{nu}, P=0.03)$ and lower parasympathetic modulation ( $28.79 \pm 4.37$ vs $41.77 \pm 3.47 \mathrm{nu}, P=0.03)$ compared to physically active older adult subjects during isometric handgrip exercise. Regarding muscle vasodilation response, there was an increase in the skeletal muscle blood flow in the second $(4.1 \pm 0.5$ vs $3.7 \pm 0.4 \mathrm{~mL} / \mathrm{min}$ per $100 \mathrm{~mL}, P=0.01)$ and third minute $(4.4 \pm 0.4 \mathrm{vs} 3.9 \pm 0.3 \mathrm{~mL} / \mathrm{min}$ per $100 \mathrm{~mL}, P=0.03)$ of handgrip exercise in active older adults. The results indicate that regular physical activity improves neurovascular control of muscle blood flow and cardiac autonomic response during isometric handgrip exercise in healthy older adult subjects.

Keywords: forearm blood flow, handgrip exercise, heart rate variability, sympathetic, parasympathetic, aging

\section{Introduction}

Regardless of several comorbidities, the aging process changes autonomic cardiovascular control leading to a sympathovagal imbalance, ${ }^{1,2}$ favoring endothelial dysfunction due to a reduction in endothelium-dependent vasodilation. ${ }^{3}$ Moreover, the sympathetic nervous system has important control on peripheral blood flow through the vasoconstriction mediated by alpha-adrenergic receptors. ${ }^{4}$ These disorders contribute to the development of cardiovascular events throughout the aging process and are one of the major causes of death in the older adult population. ${ }^{5}$ 
However, regular exercise training is an effective nonpharmacological therapy to improve autonomic dysfunction in the older adult population, ${ }^{2,6}$ even with the presence of cardiovascular diseases such as heart failure and atrial fibrillation. ${ }^{7,8}$ For instance, higher cardiac sympathetic activity is an important predictor of mortality in this population, and exercise training improves this parameter, thereby decreasing the risk of negative outcomes. ${ }^{9}$ In addition, recent studies have found that leisure physical activities are effective in reducing vascular resistance and increasing muscle vasodilator response in middle-aged and older women after 4 months of exercise training ${ }^{10}$ associated with increased endotheliumdependent vasodilation (evaluated through the relationship between mean blood pressure and blood flow) after at least 6 months of exercise training. ${ }^{11}$ However, no studies have evaluated whether the neurovascular control of muscle blood flow and cardiac autonomic activity could be modified with regular physical activity in healthy older adults.

Therefore, it is important to evaluate the integrity of the cardiovascular system by using a sympathetic excitatory maneuver by isometric exercise (handgrip maneuver), which stimulates the central command through the mechanoreceptors and metaboreceptors localized in the peripheral muscles. ${ }^{12}$ Handgrip exercise activity activates the $\beta$-adrenergic system, which stimulates the release of neuromediated nitric oxide, thus increasing muscle vasodilation. ${ }^{13}$ To test the hypothesis that regular physical exercise could improve the cardiac sympathetic and vasodilatation responsiveness in an older adult population, heart rate variability (HRV) was assessed at rest and during sustained isometric handgrip exercise in this population, and the cardiac autonomic response and muscle vasodilation were compared in physically active and sedentary older adults during isometric exercise.

\section{Methods}

\section{Study population}

All participants were selected from Sport and Leisure Activities Project for Older Adults of the Department of Physical Education at the Federal University of Paraiba, Family Health Program, and Basic Health Units, João Pessoa, Paraíba, Brazil. Six hundred and ten older adults were evaluated through their medical records in the Department of Physical Education. Of the 610 older adult subjects, 27 participants who met the inclusion criteria for this study were contacted and were invited to participate in this study. They answered the International Physical Activity Questionnaire to evaluate the level of physical activity. ${ }^{14}$ From these 27 participants, two were excluded because they were classified as "very active" and three for being "insufficiently active." In addition, two participants were excluded due to artifacts in the electrocardiography (ECG) signal acquisition. Finally, 20 older adults were included, of whom 10 were physically active and 10 were sedentary. The physically active group had an average of $8.0 \pm 1.1$ years of regular physical exercise. Figure 1 shows the study flowchart.

The participants did not use any medications that could affect control of their heart rate or muscle blood flow. Clinical examinations, including medical history, physical examination, and biochemical blood (blood count, glucose, total cholesterol and fractions, and triglycerides), were assessed for all participants, and they were considered healthy. Individuals aged $>60$ years were included in this

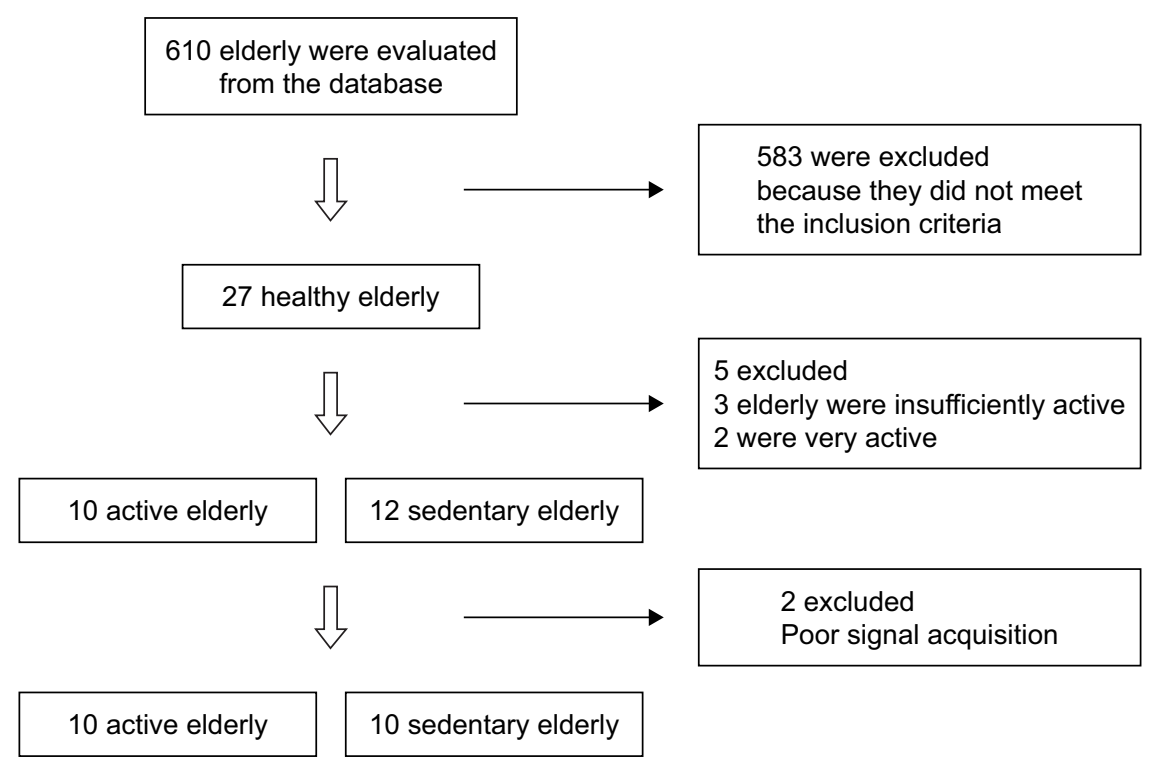

Figure I Flowchart of the study participants. 
study and were classified as physically active or sedentary. Smokers, athletes, and individuals on any medication were excluded. All subjects were free of obesity, dyslipidemia, diabetes mellitus, peripheral autonomic neuropathy, cardiovascular disease, and chronic obstructive or restrictive pulmonary disease. The older adult groups were matched for age, body mass index (BMI), biochemical, and hemodynamic characteristics.

This study was approved by the Research Ethics Committee in Human Beings of the Lauro Wanderley University Hospital at the Federal University of Paraiba (Protocol No 0041). Participants were informed about the objectives and the research purposes, and written informed consent was obtained from all the subjects.

\section{Measurements and analysis} Forearm blood flow (FBF)

FBF was measured by venous occlusion plethysmography (Hokanson EC6, Plethysmograph; Hokanson, Bellevue, WA, USA) as previously described. ${ }^{15}$ Next, a mercury-filled silastic tube attached to a low-pressure transducer was placed around the forearm and connected to a plethysmography device. The nondominant arm was elevated above the heart level to ensure adequate venous drainage. Sphygmomanometer cuffs were placed around the wrist and upper arm. At 20-second intervals, the upper cuff was inflated above venous pressure $(60 \mathrm{mmHg})$ for 10 seconds, followed by 10 seconds of release. FBF (in milliliters per minute per 100 milliliters) was determined on the basis of a minimum of four separate readings.

\section{Heart rate and blood pressure}

The cardiac electric activity (CEA) can be obtained in bipolar (DI, DII and DIII) and unipolar leads (aVR, aVL, aVF). In this study, we evaluated the CEA in bipolar leads (DII). Blood pressure was noninvasively measured by oscillometric method (Dixtal DX 2020). The cuff was placed around the left ankle and was inflated every 60 minutes throughout the experiment.

\section{Respiration}

The respiration signal was obtained with a respiratory belt (Model 1132 Pneumotrace II ${ }^{\mathrm{TM}}$, Morro Bay, CA, USA), containing bilateral sensors that capture the respiratory signal through the thoracic distensibility from the breathing pattern.

All signals were preamplified with a frequency of $1,000 \mathrm{~Hz}$ and stored in a computer. WINDAQ was used to record the signals (DATAQ Instruments DI-200 Acquisition, Akron, OH, USA).

\section{Spectral analysis}

Analysis of autonomic nervous system (ANS) modulation was assessed by ECG R-R interval PSA computed by an autoregressive algorithm. ${ }^{16}$ The heart rate was automatically identified by using WINDAQ DI-200 algorithm with a time series (tachogram), which was used to perform the spectral analysis. The power spectral density was integrated in two frequency bands of interest called high frequency (HF: 0.15-0.4 Hz) and low frequency (LF: 0.03-0.15 Hz). The autonomic balance was obtained by dividing the absolute LF and HF components. ${ }^{17}$ Respiratory rate, which works on a HF band $(\sim 0.2 \mathrm{~Hz})$, was evaluated to verify the possible influence of respiratory mechanics on the LF band of heart rate.

\section{Symbolic analysis}

This nonlinear analysis of R-R intervals classifies them into six levels (0-5) and groups them into sequences of three symbols called triads. These triads were classified into four families (V, variation; LV, like variation; UV, unlike variation): 1) $0 \mathrm{~V} \%$ - standard unchanged (three identical symbols: 111 and 000), which represents sympathetic modulation index; 2) $1 \mathrm{~V} \%$ - standard with one variation (two similar symbols and one different: 001, 100, 110, and 011), which indicates association with the parasympathetic modulation; 3) $2 \mathrm{LV} \%$ - standard with two equal variations (three symbols form ascending or descendants ramps); and 4) $2 \mathrm{UV} \%$ standard with two different variations (three symbols forming peaks or valleys). The results of the $2 \mathrm{LV} \%$ and $2 \mathrm{UV} \%$ patterns were summed and displayed as 2V\% (101 and 010) and associated with parasympathetic modulation. ${ }^{18,19}$ Total variance was evaluated by the time domain method. The distribution complexity of HRV was assessed by Shannon entropy.

\section{Sympathetic excitatory maneuver by isometric exercise}

The sympathetic excitatory maneuver by isometric exercise (handgrip) was performed by a handgrip device ( $\mathrm{Jamar}^{\mathrm{B}}$ $5030 \mathrm{~J} 1$ model). The participants were asked to perform the handgrip exercise for 3 minutes at 30\% maximal voluntary contraction, which was obtained from the peak force of three consecutive times before the experimental protocol as suggested by Coldham et al. ${ }^{20}$ The sustained contraction with isometric exercise has been used to evaluate the autonomic activity and muscle vasodilation responses. ${ }^{13,21}$

\section{Experimental protocol}

The volunteers were instructed not to perform strenuous efforts, keep food intake, and rest as usual and not to ingest stimulant drinks (coffee, chocolate, or alcohol) within 
24 hours prior to the experiment. After instrumentation (electrocardiogram, respiratory belt, blood pressure, and venous occlusion plethysmography), the participants remained at rest for 10 minutes in the supine position. After this period, all variables were recorded during 10 minutes of baseline followed by 3 minutes of isometric exercise.

\section{Statistical analysis}

Normality and homogeneity tests were used to test the data distribution by Shapiro-Wilk and Levene tests, respectively. Student's $t$-test for unpaired samples was used for the inferential analysis of the general characteristics (effect size $=0.051$ and Cohen's $d=1.17)$. Chi-square test $\left(\chi^{2}\right)$ was used to analyze the differences in gender proportions between the groups. Cardiac autonomic parameters were analyzed by Wilcoxon and Mann-Whitney tests. The muscle vasodilation response was evaluated by repeated-measures analysis of variance followed by Tukey's post hoc test, with an effect size of 0.68 . Data are presented as mean \pm standard error and a significance level of $P<0.05$ was accepted.

\section{Results}

Table 1 shows the general characteristics of the sample. There were no differences for gender, age, weight, height, and BMI.

Table I Baseline resting characteristics

\begin{tabular}{|c|c|c|c|}
\hline Variables & $\begin{array}{l}\text { Active older } \\
\text { adults }(n=10)\end{array}$ & $\begin{array}{l}\text { Sedentary } \\
\text { older adults } \\
(n=10)\end{array}$ & $P$-value \\
\hline Gender, F/M & $7 / 3$ & $7 / 3$ & 1.000 \\
\hline Age, years & $68.00 \pm 2.41$ & $66.50 \pm 1.97$ & 0.635 \\
\hline Height, m & $1.59 \pm 0.03$ & $1.58 \pm 0.03$ & 0.883 \\
\hline Weight, kg & $60.00 \pm 4.10$ & $61.78 \pm 3.44$ & $0.74 I$ \\
\hline $\mathrm{BMI}, \mathrm{kg} / \mathrm{m}^{2}$ & $23.6 I \pm 0.94$ & $24.59 \pm 0.64$ & 0.399 \\
\hline Hemoglobin, g/dL & $13.60 \pm 0.47$ & $13.06 \pm 0.40$ & 0.403 \\
\hline Erythrocytes, $\times 10^{3} / \mathrm{mm}^{3}$ & $4,453.75 \pm I I 5.47$ & $4,391.50 \pm 156.97$ & 0.771 \\
\hline Hematocrit, \% & $41.10 \pm 1.05$ & $39.37 \pm 1.13$ & 0.308 \\
\hline Glucose, mg/dL & $91.40 \pm 3.81$ & $91.60 \pm 3.05$ & $0.87 \mid$ \\
\hline Total cholesterol, mg/dL & $211.44 \pm 10.42$ & $216.30 \pm 9.07$ & 0.735 \\
\hline LDL-c, mg/dL & $135.74 \pm 8.6$ & $|3| .08 \pm 8.28$ & 0.772 \\
\hline HDL-c, mg/dL & $49.10 \pm 2.41$ & $47.86 \pm 3.77$ & 0.795 \\
\hline Triglycerides, mg/dL & $122.89 \pm 6.74$ & || $8.20 \pm 5.6 \mid$ & 0.607 \\
\hline $\mathrm{SBP}, \mathrm{mmHg}$ & $128.14 \pm 2.18$ & $126.55 \pm 3.24$ & 0.253 \\
\hline $\mathrm{DBP}, \mathrm{mmHg}$ & $62.34 \pm 2.7 \mid$ & $59.39 \pm 3.07$ & 0.716 \\
\hline $\mathrm{MBP}, \mathrm{mmHg}$ & $84.27 \pm 2.53$ & $81.77 \pm 3.12$ & 0.542 \\
\hline $\mathrm{HR}, \mathrm{bpm}$ & $66 \pm 3$ & $69 \pm 2$ & 0.133 \\
\hline
\end{tabular}

Note: Values are presented as mean \pm standard error.

Abbreviations: F, female; M, male; BMI, body mass index; LDL-c, low-density lipoprotein cholesterol; HDL-c, high-density lipoprotein cholesterol; SBP, systolic blood pressure; DBP, diastolic blood pressure; MBP, mean blood pressure; HR, heart rate.

\section{Baseline cardiac autonomic measurements}

At baseline, cardiac sympathetic modulation (LF component) was higher in sedentary than in active older adults $(P=0.018$, Table 2). Cardiac parasympathetic activity (1V\%) was higher in active than in sedentary older adults $(P=0.030$, Table 2$)$. There was no significant difference in HF component and cardiac autonomic balance ( $\mathrm{LF} / \mathrm{HF})$ between groups $(P=$ NS, Table 2$)$.

\section{Cardiac autonomic response to isometric exercise}

While comparing the autonomic response to isometric exercise, both the groups showed a similar increase in cardiac sympathetic activity (LF component, within groups, $P=0.004$ for both), cardiac autonomic balance (LF/HF component, within groups, $P<0.004$ for both), and a reduction of cardiac

Table 2 Symbolic and spectral analysis of heart rate at baseline resting and during the maneuver with isometric exercise

\begin{tabular}{|c|c|c|}
\hline Variables & $\begin{array}{l}\text { Active older } \\
\text { adults }(n=10)\end{array}$ & $\begin{array}{l}\text { Sedentary older } \\
\text { adults }(n=10)\end{array}$ \\
\hline \multicolumn{3}{|c|}{ Symbolic analysis } \\
\hline \multicolumn{3}{|c|}{ Variance, $\mathrm{ms}$} \\
\hline Baseline & $\mathrm{I}, 438.64 \pm 448.90$ & $\mathrm{I}, 402.92 \pm 385.14$ \\
\hline Handgrip & $5,660.91 \pm 1,626.72 *$ & $4,381.35 \pm 1,852.87$ \\
\hline \multicolumn{3}{|c|}{ Shannon entropy } \\
\hline Baseline & $3.39 \pm 0.09$ & $3.24 \pm 0.13$ \\
\hline Handgrip & $3.30 \pm 0.17$ & $3.28 \pm 0.17$ \\
\hline \multicolumn{3}{|l|}{ OV\% } \\
\hline Baseline & $25.06 \pm 2.67$ & $29.66 \pm 6.23$ \\
\hline Handgrip & $35.95 \pm 5.27$ & $36.95 \pm 4.75 *$ \\
\hline \multicolumn{3}{|l|}{ IV\% } \\
\hline Baseline & $50.26 \pm 1.34^{\dagger}$ & $44.85 \pm 2.42$ \\
\hline Handgrip & $42.22 \pm 3.53$ & $43.24 \pm 2.4 I$ \\
\hline \multicolumn{3}{|l|}{$2 \mathrm{~V} \%$} \\
\hline Baseline & $24.68 \pm 3.00$ & $25.49 \pm 5.42$ \\
\hline Handgrip & $21.83 \pm 4.58$ & $19.80 \pm 3.28$ \\
\hline \multicolumn{3}{|c|}{ Spectral analysis } \\
\hline \multicolumn{3}{|c|}{ LF, nu } \\
\hline Baseline & $50.45 \pm 3.55$ & $63.13 \pm 3.3 \mathrm{I}^{\dagger}$ \\
\hline Handgrip & $58.30 \pm 3.50 *$ & $71.29 \pm 4.40^{*, \dagger}$ \\
\hline \multicolumn{3}{|l|}{$\mathrm{HF}, \mathrm{nu}$} \\
\hline Baseline & $49.35 \pm 3.56$ & $42.17 \pm 4.24$ \\
\hline Handgrip & $41.77 \pm 3.47^{*}$ & $28.79 \pm 4.37^{*, \dagger}$ \\
\hline \multicolumn{3}{|l|}{$\mathrm{LF} / \mathrm{HF}$} \\
\hline Baseline & $1.15 \pm 0.17$ & $1.63 \pm 0.26$ \\
\hline Handgrip & $1.58 \pm 0.22 *$ & $3.13 \pm 0.76 *$ \\
\hline
\end{tabular}

Notes: Values are presented as mean \pm standard error. *Difference within groups; $P<0.05$. 'Difference between groups; $P<0.05$. LF/HF, cardiac autonomic balance; $0 \mathrm{~V} \%$, standard unchanged; IV\%, standard with a variation; 2IV\%, standard with two equal variations.

Abbreviations: ms, milliseconds; LF, low frequency; HF, high frequency; nu, normalized units. 
parasympathetic modulation (HF component, within groups, $P=0.004$ for both, Table 2).

Interestingly, the variance (HRV in the time domain) significantly increased in the active older adults. Also, the variance (HRV in the time domain) significantly increased at the baseline resting autonomic response to isometric exercise just in the active older adult group $(P=0.028)$. Therefore, cardiac sympathetic activity measured by symbolic analysis (standard 0V\%) significantly increased only in the sedentary older adult group (between groups, $P=0.030$ ). In addition, the sedentary older adult group showed higher cardiac sympathetic modulation (LF component, $P=0.033$ ) and lower parasympathetic modulation (HF component, $P=0.032$ ) than the active older adult group. No significant difference in cardiac autonomic balance $(\mathrm{LF} / \mathrm{HF})$ was found between the groups $(P=0.066$, Table 2$)$.

\section{Baseline FBF and the response to isometric exercise}

Regarding FBF at baseline, there was no significant difference between active and sedentary older adults $(2.9 \pm 0.2$ vs $2.8 \pm 0.2 \mathrm{~mL} / \mathrm{min}$ per $100 \mathrm{~mL}$, respectively, $P=0.800$, Figure 2). On the other hand, a significant increase in muscle vasodilation response was observed in the active older adult group at 2 minutes $(4.1 \pm 0.5$ vs $3.7 \pm 0.4 \mathrm{~mL} / \mathrm{min}$ per $100 \mathrm{~mL}$; $P=0.010)$ and at 3 minutes $(4.4 \pm 0.4$ vs $3.9 \pm 0.3 \mathrm{~mL} / \mathrm{min}$ per $100 \mathrm{~mL} ; P=0.030$ ) of isometric exercise (Figure 2).

\section{Discussion}

Two findings of this study support the hypothesis that regular exercise training improves autonomic response and muscle vasodilatation at rest and during isometric exercise in healthy older adults, as shown in Table 1. First, sedentary

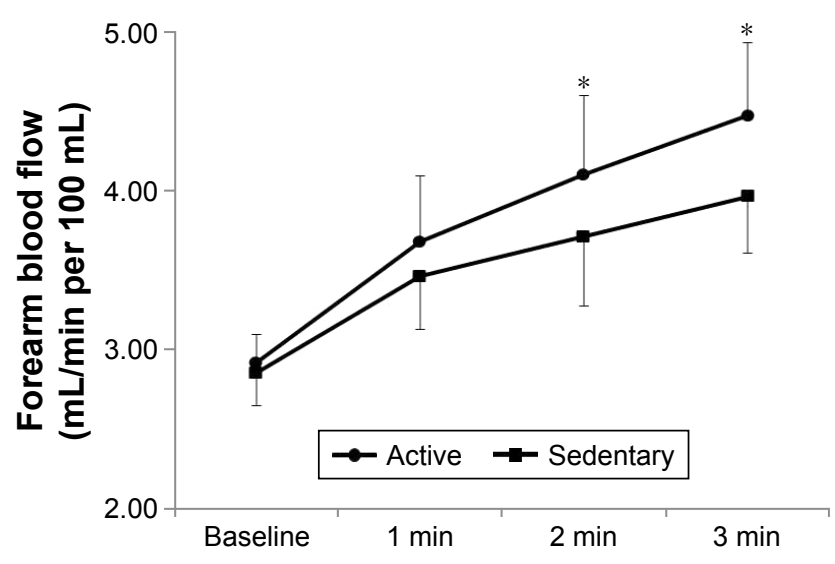

Figure 2 Muscle vasodilation response in the forearm in active and sedentary older adults during maneuver with isometric exercise.

Note: *From baseline, $P<0.05$ (within group). older adults showed higher cardiac sympathetic hyperactivity during isometric exercise than active older adults. In active older adults, the variance increased significantly during the handgrip maneuver. Second, the muscle vasodilation response in the forearm during isometric exercise was higher within the active older adult group.

Several studies have also shown that exercise training (three times per week, for 6 months) is effective in reducing cardiac sympathetic activity in healthy older adults, ${ }^{6,22}$ and exercise training of three times per week for 10 weeks increased muscle vasodilation in hypertensive older adults ${ }^{10}$ and at baseline resting in healthy older adults. It is known that higher cardiac sympathetic activity is an important predictor of mortality in this population. ${ }^{9}$ Moreover, exercise training can preserve functional sympatholysis with aging by improving blood flow distribution within the active muscle associated with increased aerobic metabolism. ${ }^{23}$ However, none of the studies to our knowledge have compared the response of acute isometric exercise on muscle vasodilation between sedentary and physically active older adults. Curiously, in this study, baseline resting muscle blood flow of active older adults showed no difference when compared to sedentary older adults. However, a similar result was also found by Dinenno et al, ${ }^{24}$ who observed that aerobic exercise training in older adults did not change limb blood flow at resting baseline. Dinenno et al evaluated "physically active" (light/moderate physical activity three or more times per week) and "endurance trained" (vigorous aerobic endurance exercise five or more times per week and active in local road running races) conditions in 55- to 75-year-old adults. Therefore, the muscle vasodilation response during isometric exercise in active older adults seems to have an important clinical significance. It is known that during exercise, nitric oxide plays an important role in muscle-induced vasodilation in older adult subjects. ${ }^{25}$ In this context, regular aerobic exercise training attenuates arterial stiffness associated with aging and contributes to the increase in arterial compliance in older adults. ${ }^{26}$ Moreover, shear stress during exercise is a powerful trigger to stimulate the release of endotheliumderived relaxing factors such as nitric oxide. ${ }^{27}$ The release of nitric oxide has a clinical impact on older adult subjects. For instance, nitric oxide stimulates vagal modulation and inhibits sympathetic neurotransmission. ${ }^{28,29}$ Nitric oxide has a role in the control of heart rate either by modulation of the sinoatrial node or by the autonomic nervous system. ${ }^{30}$ The present study demonstrated that cardiac autonomic control is improved in active older adults. Consequently, it can be speculated that the neurovascular improvement may be 
related to the synthesis and release of nitric oxide, which are reduced in aging, and it appears to be positively regulated by physical exercise, as shown by Maeda et al. ${ }^{31}$ Maeda et $\mathrm{al}^{31}$ suggested that 3 months of exercise training increases nitric oxide production in older adults, which may have beneficial effects on the cardiovascular system. The authors measured plasma nitric oxide concentration.

During isometric exercise, several reflexes are activated leading to increased sympathetic nerve activity. Before beginning the exercise, the central neural activity known as central command is activated leading to increased sympathetic constrictor activity. Second, the mechanoreceptors are stimulated by muscle contraction contributing to the increase of sympathetic nerve activity. ${ }^{32}$ Finally, the metabolites accumulated during exercise stimulate muscle metaboreceptors (chemosensitive afferent nerve fibers), which increase sympathetic activity for both exercised and not exercised muscles. Therefore, metaboreflex is the main reflex mechanism that activates the sympathetic nervous system during isometric exercise. . $^{33,34}$

This study found that sedentary older adult subjects presented increased cardiac sympathetic activity and reduced cardiac parasympathetic activity compared to age-matched active older adults. This result could be justified due to higher sympathetic activity at rest and possibly by an impaired metaboreflex control in the sedentary older adults. It is known that metaboreflex sensitivity is impaired with aging ${ }^{35}$ and that exercise training improves this sensitivity in cardiovascular diseases such as in heart failure. ${ }^{36}$ Furthermore, the aging process is associated with impaired baroreflex and chemoreflex sensitivity, ${ }^{37,38}$ and both are positively modulated by regular aerobic exercise training. ${ }^{39,40}$ Although these mechanisms were not investigated in this study, it could be expected that the improvement in cardiac autonomic control and skeletal blood flow in the active older adults is associated with these reflex mechanisms. This is an interesting topic for future investigations.

The findings of this study have important clinical relevance. Higher cardiac sympathetic activity is a predictor of mortality in older adults, ${ }^{9}$ in addition to other cardiovascular diseases. ${ }^{41,42}$ Increased cardiac sympathetic outflow predisposes one to cardiac arrhythmias and sudden death. Likewise, FBF is a predictor of mortality in patients with heart failure. ${ }^{43}$ In addition, reduced muscle blood flow may represent a reduction in muscle perfusion and functional capacity in healthy older adults. ${ }^{44}$ Thus, cardiovascular adjustments stimulated by regular physical exercise can reduce the risk of comorbidities associated with aging.
This study has some limitations. The population studied was by convenience and the level of physical activity was obtained by questionnaire. The sample size is probably too small, although the results reported are statistically significant. In addition, it was not possible to control the dosage of the nitric oxide to our older adults. This was a cross-sectional study, and only the physical activity level was assessed. Other aspects such as dietary habits and stress level should be emphasized in further studies.

\section{Conclusion}

Regular physical exercise improved cardiac sympathetic and parasympathetic activity, associated with muscle vasodilation at rest and during isometric exercise. Therefore, these results have a clinical impact, since they can reduce cardiovascular risk in healthy older adults.

\section{Acknowledgments}

The authors thank the coordinators of the Sport and Leisure Activities Project for Older Adults of the Department of Physical Education at the Federal University of Paraiba. This study was supported by Conselho Nacional de Desenvolvimento Científico e Tecnológico MCT/CNPq 15/2007 (485001/2007-1), and ASO was supported by Coordenação de Aperfeiçoamento de Pessoal de Nível Superior (CAPES) (REUNI 2009-2010).

\section{Disclosure}

The authors report no conflicts of interest in this work.

\section{References}

1. Melo RC, Santos MDB, Silva E, et al. Effects of age and physical activity on the autonomic control of heart rate in healthy men. Braz J Med Biol Res. 2005;38(9):1331-1338.

2. Nascimento L, Santos AC, Lima A, Ritti-Dias R, Brasileiro-Santos MS. Comparação da análise simbólica da variabilidade da frequência cardíaca entre mulheres fisicamente ativas de meia-idade e idosas. [Symbolic analysis comparation of heart rate variability in middleaged and older physically active women]. Rev Bras Ativ Fis Saúde. 2013;18(2):253-259.

3. Al-Shaer MH, Choueiri NE, Correia ML, Sinkey CA, Barenz TA, Haynes WG. Effects of aging and atherosclerosis on endothelial and vascular smooth muscle function in humans. Int J Cardiol. 2006;109(2): 201-206.

4. La Favor JD, Kraus RM, Carrithers JA, Roseno SL, Gavin TP, Hickner RC. Sex differences with aging in nutritive skeletal muscle blood flow: impact of exercise training, nitric oxide, and $\alpha$-adrenergicmediated mechanisms. Am J Physiol Heart Circ Physiol. 2014;307(4): H524-H532.

5. Seals DR, Dinenno FA. Collateral damage: cardiovascular consequences of chronic sympathetic activation with human aging. Am J Physiol Heart Circ Physiol. 2004;287(5):H1895-H1905.

6. Madden KM, Levy WC, Stratton J. Exercise training and heart rate variability in older adult female subjects. Clin Invest Med. 2006; 29(1):20-28. 
7. Selig SE, Carey MF, Menzies DG, et al. Moderate-intensity resistance exercise training in patients with chronic heart failure improves strength, endurance, heart rate variability, and forearm blood flow. J Card Fail. 2004;10(1):21-30.

8. Hegbom F, Sire S, Heldal M, Orning OM, Stavem K, Gjesdal K. Shortterm exercise training in patients with chronic atrial fibrillation: effects on exercise capacity, AV conduction, and quality of life. J Cardiopulm Rehabil. 2006;26(1):24-29.

9. Tsuji H, Venditti FJ, Manders ES, et al. Reduced heart rate variability and mortality risk in an elderly cohort. The Framingham Heart Study. Circulation. 1994;90(2):878-883.

10. Dantas FFO, Cabral TG, Silvestre ACOM, Batista RMF, Santos MSB, Santos AC. Effectiveness of leisure physical activities in vasodilatory response and blood pressure in middle-aged and elderly women. J Exerc Physiol Online. 2015;18(2):66-77.

11. Sanders K, Maresh CM, Ballard KD, et al. Habitual exercise may maintain endothelium-dependent dilation in overweight postmenopausal women. J Aging Phys Act. 2015;23(1):40-46.

12. Ueno LM, Frazzatto ES, Batalha LT, et al. Alpha2B-adrenergic receptor deletion polymorphism and cardiac autonomic nervous system responses to exercise in obese women. Int J Obes. 2006;30(2):214-220.

13. Reed AS, Tschakovsky EM, Minson CH, et al. Skeletal muscle vasodilatation during sympathoexcitation is not neurally mediated in humans. J Physiol. 2000;525(1):253-262.

14. Craig CL, Marshall AL, Sjostrom M, et al. International physical activity questionnaire: 12-country reliability and validity. Med Sci Sports Exerc. 2003;35(8):1381-1395.

15. Taylor JA, Joyner MJ, Chase PB, Seals DR. Differential control of forearm and calf vascular resistance during one-leg exercise. $J \mathrm{Appl}$ Physiol. 1989;67(5):1791-1800.

16. Zaza A, Lombardi F. Autonomic indexes based on the analysis of heart rate variability: a view from the sinus node. Cardiovasc Res. 2001;50: 434-442.

17. Sleight P, La Rovere MT, Mortara A, et al. Physiology and pathophysiology of heart rate and blood pressure variability in humans: is power spectral analysis largely an index of baroreflex gain? Clin Sci. 1995;88(1):103-109

18. Cysarz D, Van Leeuwen P, Edelhäuser F, Montano N, Somers VK, Porta A. Symbolic transformations of heart rate variability preserve information about cardiac autonomic control. Physiol Meas. 2015;36(4):643-657.

19. Guzzetti S, Borroni E, Garbelli PE, et al. Symbolic dynamics of heart rate variability: a probe to investigate cardiac autonomic modulation. Circulation. 2005;112(4):465-470.

20. Coldham F, Lewis J, Lee H. The reliability of one vs. three grip trials in symptomatic and asymptomatic subjects. J Hand Ther. 2006;19(3): 318-326.

21. Ueno LM, Frazzatto ES, Batalha LT, et al. Alpha2B-adrenergic receptor deletion polymorphism and cardiac autonomic nervous system responses to exercise in obese women. Int J Obes. 2006;30(2):214-220.

22. Schuit AJ, Van Amelsvoort LG, Verheij TC, et al. Exercise training and heart rate variability in older people. Med Sci Sports Exerc. 1999; 31(6):816-821.

23. Mortensen SP, Nyberg M, Winding K, Saltin B. Lifelong physical activity preserves functional sympatholysis and purinergic signalling in the ageing human leg. J Physiol. 2012;590(23):6227-6236.

24. Dinenno FA, Seals DR, DeSouza CA, Tanaka H. Age-related decreases in basal limb blood flow in humans: time course, determinants and habitual exercise effects. J Physiol. 2001;531(2):573-579.

25. Trinity JD, Wray DW, Witman MA, et al. Contribution of nitric oxide to brachial artery vasodilation during progressive handgrip exercise in the elderly. Am J Physiol Regul Integr Comp Physiol. 2013;305(8): R893-R899.
26. Tanaka H, Dinenno FA, Monahan KD, et al. Aging, habitual exercise, and dynamic arterial compliance. Circulation. 2000;102(11):1270-1275.

27. Kingwell BA. Nitric oxide-mediated metabolic regulation during exercise: effects of training in health and cardiovascular disease. FASEBJ. 2000;14(12):1685-1696.

28. Boo YC, Jo H. Flow-dependent regulation of endothelial nitric oxide synthase: role of protein kinases. Am J Physiol Cell Physiol. 2005;285(3): C499-C508.

29. Elvan A, Rubart M, Zipes DP. NO modulates autonomic effects on sinus discharge rate and AV nodal conduction in open-chest dogs. Am J Physiol. 1997;272(1):H263-H271.

30. Sweeney C, Markos F. The role of neuronal nitric oxide in the vagal control of cardiac interval of the rat heart in vitro. Auton Neurosci. 2004; 111(2):110-115.

31. Maeda S, Tanabe T, Otsuki T, et al. Moderate regular exercise increases basal production of nitric oxide in elderly women. Hypertens Res. 2004; 27(12):947-953.

32. Vissing SF, Scherrer U, Victor RG. Stimulation of skin sympathetic nerve discharge by central command: differential control of sympathetic outflow to skin and skeletal muscle during static exercise. Circ Res. 1991;69(1):228-238.

33. Middlekauff HR, Nitzsche EU, Nguyen AH, Hoh CK, Gibbs GG. Modulation of renal cortical blood flow during static exercise in humans. Circ Res. 1997;80(1):62-68.

34. Ray CA, Mark AL. Sympathetic nerve activity to nonactive muscle of the exercising and no exercising limb. Med Sci Sports Exerc. 1995; 27(2):183-187.

35. Markel TA, Daley JC, Hogeman CS, et al. Aging and the exercise pressor reflex in humans. Circulation. 2003;107(5):675-678.

36. Antunes-Correa LM, Nobre TS, Groehs RV, et al. Molecular basis for the improvement in muscle metaboreflex and mechanoreflex control in exercise-trained humans with chronic heart failure. Am J Physiol Heart Circ Physiol. 2014;307(11):H1655-H1666.

37. Fauvel JP, Cerutti C, Mpio I, Ducher M. Aging process on spectrally determined spontaneous barorefex sensitivity: a 5-year prospective study. Hypertension. 2007;50(3):543-546.

38. Poulin MJ, Cunningham DA, Paterson DH, Kowalchuk JM, Smith WD. Ventilatory sensitivity to $\mathrm{CO} 2$ in hyperoxia and hypoxia in older aged humans. J Appl Physiol. 1993;75(5):2209-2216.

39. Laterza MC, de Matos LD, Trombetta IC, et al. Exercise training restores baroreflex sensitivity in never-treated hypertensive patients. Hypertension. 2007;49(6):1298-1306.

40. Li YL, Ding Y, Agnew C, Schultz HD. Exercise training improves peripheral chemoreflex function in heart failure rabbits. $J$ Appl Physiol. 2008;105(3):782-790.

41. Kleiger RE, Miller JP, Bigger JT, Moss AJ. Decreased heart rate variability and its association with increased mortality after acute myocardial infarction. Am J Cardio. 1987;59(4):256-262.

42. Bigger JT, Fleiss JL, Steinman RC, Rolnitzky LM, Kleiger RE, Rottman JN. Frequency domain measures of heart period variability and mortality after myocardial infarction. Circulation. 1992;85(1): $164-171$.

43. Barretto ACP, Santos AC, Munhoz R, et al. Increased muscle sympathetic nerve activity predicts mortality in heart failure patients Int J Cardiol. 2009;135(3):302-307.

44. Dinenno FA, Jones PP, Seals DR, Tanaka H. Limb blood flow and vascular conductance are reduced with age in healthy humans: relation to elevations in sympathetic nerve activity and declines in oxygen demand. Circulation. 1999;100(2):164-170. 


\section{Publish your work in this journal}

Clinical Interventions in Aging is an international, peer-reviewed journal focusing on evidence-based reports on the value or lack thereof of treatments intended to prevent or delay the onset of maladaptive correlates of aging in human beings. This journal is indexed on PubMed Central, MedLine,

CAS, Scopus and the Elsevier Bibliographic databases. The manuscript management system is completely online and includes a very quick and fair peer-review system, which is all easy to use. Visit http://www.dovepress. com/testimonials.php to read real quotes from published authors. 